\title{
IDENTIFICACIÓN DE ZONAS DE EROSIÓN ACTIVAY Y ÁREAS DE RIESGO MEDIANTE TELEDETECCIÓN: UN EJEMPLO EN UN PAISAJE DE CÁRCAVAS SOBRE MARGAS EN EL PIRINEO CENTRAL ESPAÑOL
}

\author{
L.C. ALATORRE ${ }^{(1)}$ y S. BEGUERÍA ${ }^{(2)}$ \\ (1) Instituto Pirenaico de Ecología, CSIC \\ Campus de Aula Dei, Apdo 202, 50080 Zaragoza, España \\ (2) Estación Experimental de Aula Dei, CSIC \\ Av. Montañana, 1005, 50059, Zaragoza, España \\ correo electrónico de contacto: lalatorre@ipe.csic.es
}

\begin{abstract}
RESUMEN. Identificar áreas con erosión activa a escala de cuenca puede ser muy útil para la gestión medioambiental, siendo un requisito para la planificación de medidas contra la degradación del suelo y la producción de sedimentos. En este trabajo se utilizaron técnicas de teledetección para discriminar zonas de erosión activa y de riesgo de erosión en un paisaje de cárcavas desarrolladas sobre margas del Eoceno, en la cuenca del río Ésera (Pirineo español). La distribución espacial, la escasa cobertura vegetal y el alto grado de erosión en las cárcavas han permitido discriminar tanto visual como digitalmente las cárcavas. Se utilizó el método de clasificación supervisada de máxima verosimilitud para discriminar áreas con erosión activa (cárcavas) a partir de la signatura espectral del suelo desnudo. A partir del mapa de distancias de clasificación a la categoría de cárcavas se seleccionaron dos umbrales de clasificación, basados en dos estadísticos de error (sensibilidad y especificidad), que permitieron obtener la distribución espacial de las cárcavas y las zonas de riesgo. Los resultados indican que la mayoría de las zonas de riesgo se localizan en la periferia de las zonas de cárcavas y presentan una exposición predominante de umbría, constituyendo zonas de actuación prioritaria frente al riesgo de erosión.
\end{abstract}

ABSTRACT. The identification of eroded areas at catchment scale can be very useful for environmental planning and can help to reduce land degradation and sediment yield. In this paper remote sensing techniques are used to discriminate both eroded areas and erosion risk areas in a badlands landscape developed on Eocene marls, in the Ésera River catchment (Spanish Pyrenees). The spatial distribution, the scarce vegetal cover and the high erosion level let a good visual and digital discrimination of badlands, as opposed to other land covers and surfaces. 
A maximum likelihood supervised method was used to discriminate heavily eroded areas (badlands) from scarce or densely vegetated lands, by means of the spectral signature of bare soil. The classification distance was used to obtain thresholds for eroded areas and areas at risk. Two error statistics (sensitivity and specificity) where used to determine the most adequate threshold values. The resulting map shows that most areas at risk are located surrounding the badland areas.

Palabras clave: cárcavas, margas, regolito, sensibilidad y especificidad estadística, clasificación supervisada, máxima verosimilitud, Landsat.

Key words: badlands, marls, regolith, statistical sensitivity and specificity, supervised classification, maximum likelihood, Landsat.

\section{Introducción}

Los estudios sobre la erosión se han realizado a diversas escalas espaciales, desde escalas locales a escalas regionales (Vrieling et al., 2006), proporcionado información de tipo cuantitativo (tasas de erosión) o cualitativo (p. ej. zonas de riesgo de erosión). De cara a la gestión medioambiental, resulta de gran interés la obtención de cartografías de riesgo de erosión, que permiten concentrar las actuaciones en los lugares donde éstas resultarán más adecuadas. Existe en la actualidad una gran diversidad de métodos para determinar la erosión, los cuales difieren grandemente en cuanto a la escala espacial y el propósito (Warren, 2002).

Los métodos para evaluar el riesgo de erosión a escala de cuenca y regional (10$10,000 \mathrm{~km}^{2}$ ) incluyen la aplicación de modelos de erosión y aproximaciones cualitativas mediante el uso de teledetección y sistemas de información geográfica (SIG). Merrit et al. (2003) hicieron una descripción muy exhaustiva sobre los modelos de erosión con los que se cuenta en la actualidad. Sin embargo, la aplicación de estos modelos fuera de las regiones para las cuales fueron desarrollados generalmente ha llevado a estimaciones erróneas (p ej. Brazier et al., 2000), requiriendo en muchos casos largos y complejos procesos de calibración, para adaptarlos a las condiciones particulares de la zona de estudio (Jetten et al., 1999, 2003). En muchos casos, los modelos de erosión han sido creados para escalas pequeñas y su extrapolación a escalas más grandes (cuenca o regional) no resulta sencilla (Kirkby et al., 1996; Schoorl et al., 2000; Yair y Raz-Yassif, 2004).

La utilización de teledetección y SIG para el estudio de la erosión a escala regional ha tenido una evolución creciente, con objetivos que van desde la determinación de las características de la erosión y de las superficies erosionadas, la estimación de los factores que controlan la erosión, las características del suelo y la cubierta vegetal, o el seguimiento de los procesos de erosión a lo largo del tiempo (Muchoney y Haack, 1994; Chuvieco, 
1996; Lambin, 1996). Sin embargo, en la mayoría de los casos las técnicas de teledetección se han aplicado simplemente para determinar características de la cubierta vegetal, en gran parte debido a la limitada visibilidad de la superficie del suelo en los ambientes húmedos (Vrieling, 2006).

Otros estudios han demostrado el potencial de la teledetección para determinar pautas temporales y espaciales de la erosión, así como la estimación cualitativa de zonas con erosión activa y áreas en riesgo de erosión (Pilesjo, 1992; Rode y Frede, 1997; Metternicht y Fermont, 1998; Szabo et al., 1998; Millward y Mersey, 1999; Reusing et al., 2000; Haboudane et al., 2002; Metternicht y Gonzalez, 2005). A un nivel más básico, se han realizado estimaciones del riesgo de erosión mediante la estimación del porcentaje de suelo denudo (p. ej. De Jong, 1994; Paringit y Nadaoka, 2003). Esta metodología se ha mejorado a partir de la información espectral obtenida mediante imágenes de alta resolución espacial como las de los satélites MERIS, Landsat y SPOT, y de combinarlas con otras capas de información como los mapas de pendientes generados a partir de un modelo digital del terreno (MDT), permitiendo una mejor detección de las áreas de erosión (Mathieu et al., 1997; Haboudane et al., 2002; Singh et al., 2004).

Otras metodologías que utilizan la teledetección y los SIG para delimitar zonas erosionadas son el uso de cocientes entre bandas (Pickup y Nelson, 1984; Frazier y Cheng, 1989); los índices de vegetación (Pickup y Chewings, 1988; Tripathy et al., 1996); la desagregación espectral lineal (Koch, 2000); la combinación de fuentes de reflectancia y microondas (Koopmans y Forero, 1993; Singhroy, 1995; García-Meléndez et al., 1998; Metternicht y Zinck, 1998; Singhroy et al., 1998); y las combinaciones de sensores remotos e información geocodificada (Floras y Sgouras, 1999; Mati et al., 2000; Giannetti et al., 2001; Shrimalil et al., 2001; Zinck et al., 2001; Haboudane et al., 2002; Ma et al., 2003; Symeonakis y Drake, 2004).

En el Pirineo Central español se han realizado diferentes tipos de estudios para estimar la erosión, a escala regional (Beguería, 2005 y 2006) y de cuenca (Fargas et al., 1997) mediante teledetección y modelización, y mediante la combinación de información espacial temática (litología, vegetación, pendiente, orientación, convexidad-concavidad, etc.) con ayuda de SIG, siendo sus objetivos más destacables: i) estimar cualitativamente el riesgo de erosión; ii) identificar áreas con diferente riesgo de erosión; y iii) la formulación de modelos empíricos para predecir el riesgo de erosión. Los sistemas de cárcavas en afloramientos de margas de edad Eocena se encuentran entre las áreas que presentan procesos de erosión acelerada y constituyen la principal fuente de sedimento en el Pirineo, con efectos muy importantes sobre el aterramiento de embalses (ValeroGarcés et al., 1999).

El término cárcavas es usado para describir áreas de depósitos o rocas pobremente consolidadas e intensamente afectadas por procesos de erosión superficial, caracterizadas por una elevada densidad de drenaje y la rápida evolución de gullies, rills y movimientos superficiales (Gallart et al., 2002). Las cárcavas se desarrollan dentro de una amplia gama de ambientes climáticos, particularmente en ambientes semiáridos y, en un 
menor grado, en regiones húmedas y subhúmedas (Bryan y Yair, 1982; Campbell, 1989; Regüés, 1995; Regüés et al., 1995; Pardini, 1996; Torri y Rodolfi, 2000). Casi siempre, las cárcavas están asociadas a una erosión acelerada y, por tanto, a paisajes inestables (Morgan, 1997), por lo que su fijación o la limitación de su ampliación espacial revisten un notable interés aplicado.

En las regiones subhúmedas el desarrollo de las cárcavas se ve favorecido por los factores litológicos y topográficos (Morgan, 1997; Oostwoud-Wijdenes et al., 2000), así como por la variabilidad climática estacional, especialmente como consecuencia de procesos de humectación-desecación y de hielo-deshielo, que contribuyen a alterar al regolito en profundidad y a favorecer su desagregación y fácil erosión. Es el caso de las cárcavas sobre margas del Pirineo Oriental y Central (Regüés et al., 1995; Nadal-Romero et al., 2007).

El objetivo de este trabajo es desarrollar una metodología para la determinación y análisis espacial de áreas erosionadas con intensa degradación (cárcavas) y áreas de riesgo de erosión asociadas a una escasa cubierta vegetal, utilizando el ejemplo del afloramiento Eoceno situado en la cuenca media del Río Ésera, en el Pirineo Central Español. El método propuesto se basa en técnicas de teledetección (clasificación supervisada para discriminar áreas con erosión activa) y la aplicación de la curva ROC para seleccionar el valor del umbral de clasificación y determinar el nivel de incertidumbre asociado al mapa de predicción. El método propuesto en este trabajo descansa en el mismo principio de la mayoría de los trabajos citados, dado que, en una región donde el estado natural del terreno es cubierto por vegetación, la escasez de ésta o el afloramiento directo del suelo o el material parental son indicadores claros de erosión severa. Así pues, el procedimiento de clasificación empleado se orientará a la detección de áreas con afloramiento directo del sustrato margoso y a las zonas contiguas espectralmente similares consideradas como vulnerables.

\section{2. Área de estudio}

El área de estudio se localiza aproximadamente a $23 \mathrm{~km}$ al $\mathrm{N}$ del embalse de Barasona, y está integrada por un corredor con afloramientos margosos eocenos de orientación NO-SE (Fig. 1). El rango altitudinal va desde 620 m a 2149 m (Fig. 2). El sistema de cárcavas está formado por un conjunto de típicas cárcavas de ladera, desarrolladas sobre materiales margoso-areniscosos, de textura arcillosa y fuertemente erosionables, sobre laderas convexas de pendientes moderadamente inclinadas, vertiendo a los arroyos Viu y Rialvo en la cuenca del río Ésera y al arroyo Viyacarti en la cuenca del río Isábena, afluente del anterior.

Los suelos desarrollados en la zona de estudio son Vertisoles Crómicos y presentan un perfil desarrollado de tipo A-B-C, con un horizonte ócrico en superficie y situándose el horizonte $\mathrm{C}$ a más de un metro de profundidad. El material original es rico en carbo- 


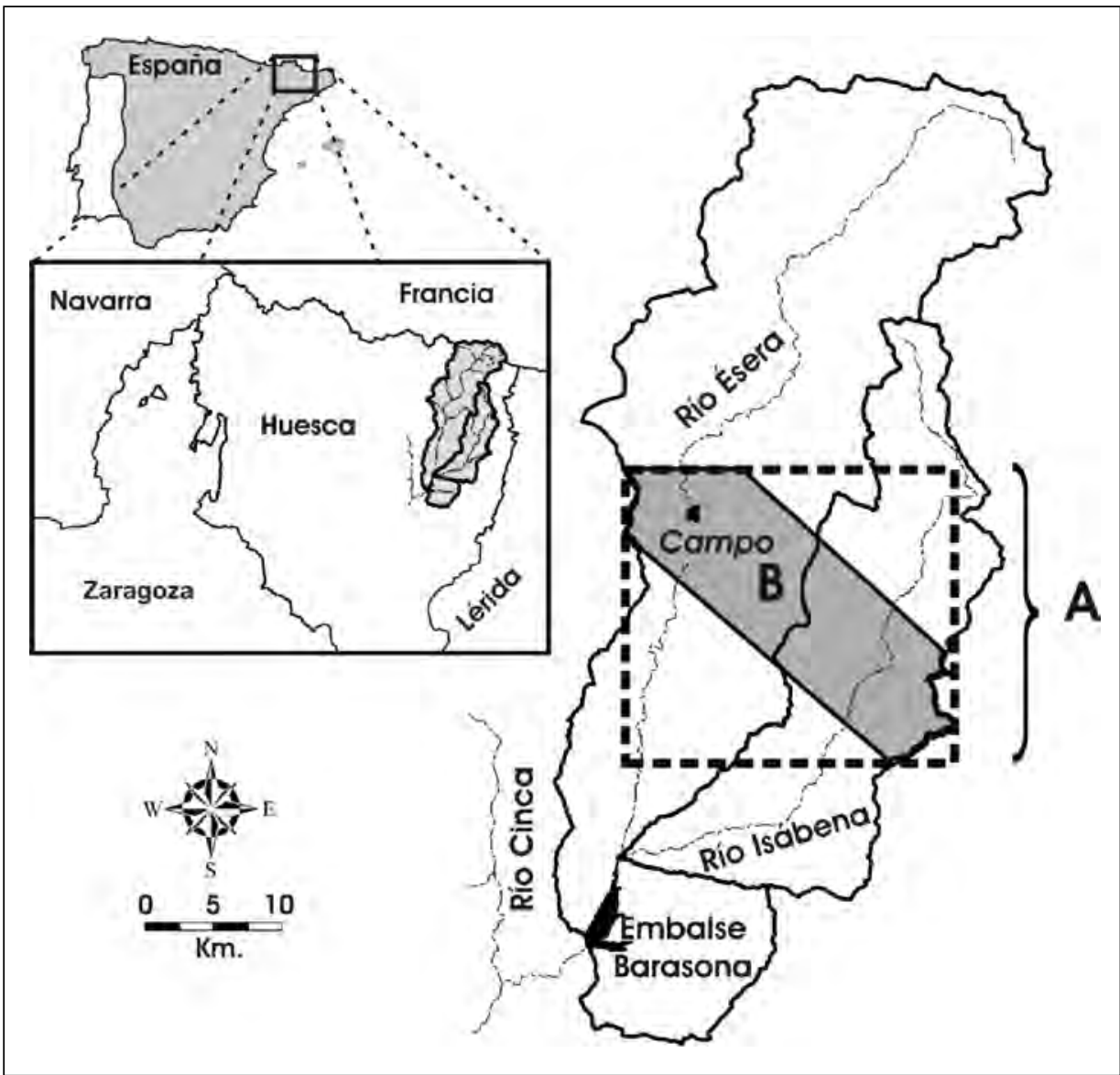

Figura 1. Ubicación de la zona de estudio: A, área que comprende la escena Landsat TM de 24 de agosto de 2006; B, localización del corredor de cárcavas sobre margas (236 km²)

nato cálcico, que se acumula en forma de nódulos de manera frecuente en los horizontes B y C. Como rasgo significativo, destaca la formación de grietas de retracción en la estación seca que pueden alcanzar más de medio metro de profundidad, lo que favorece la mezcla del horizonte superior.

El clima es de montaña, húmedo y frío, con influencias atlánticas y mediterráneas continentales (García-Ruiz et al., 1985). La temperatura media anual es de $11^{\circ} \mathrm{C}$, mientras que la precipitación se sitúa en torno a los $876 \mathrm{~mm}$ anuales (Fig. 3). La precipitación se distribuye de manera irregular a lo largo del año, con un máximo en primavera de entre 80 y $107 \mathrm{~mm} \mathrm{mes}^{-1}$ (abril-mayo, respectivamente), y un período de precipitaciones mínimas en los meses de julio y agosto, en los que la precipitación no supera los $70 \mathrm{~mm} \mathrm{mes}^{-1}$. 


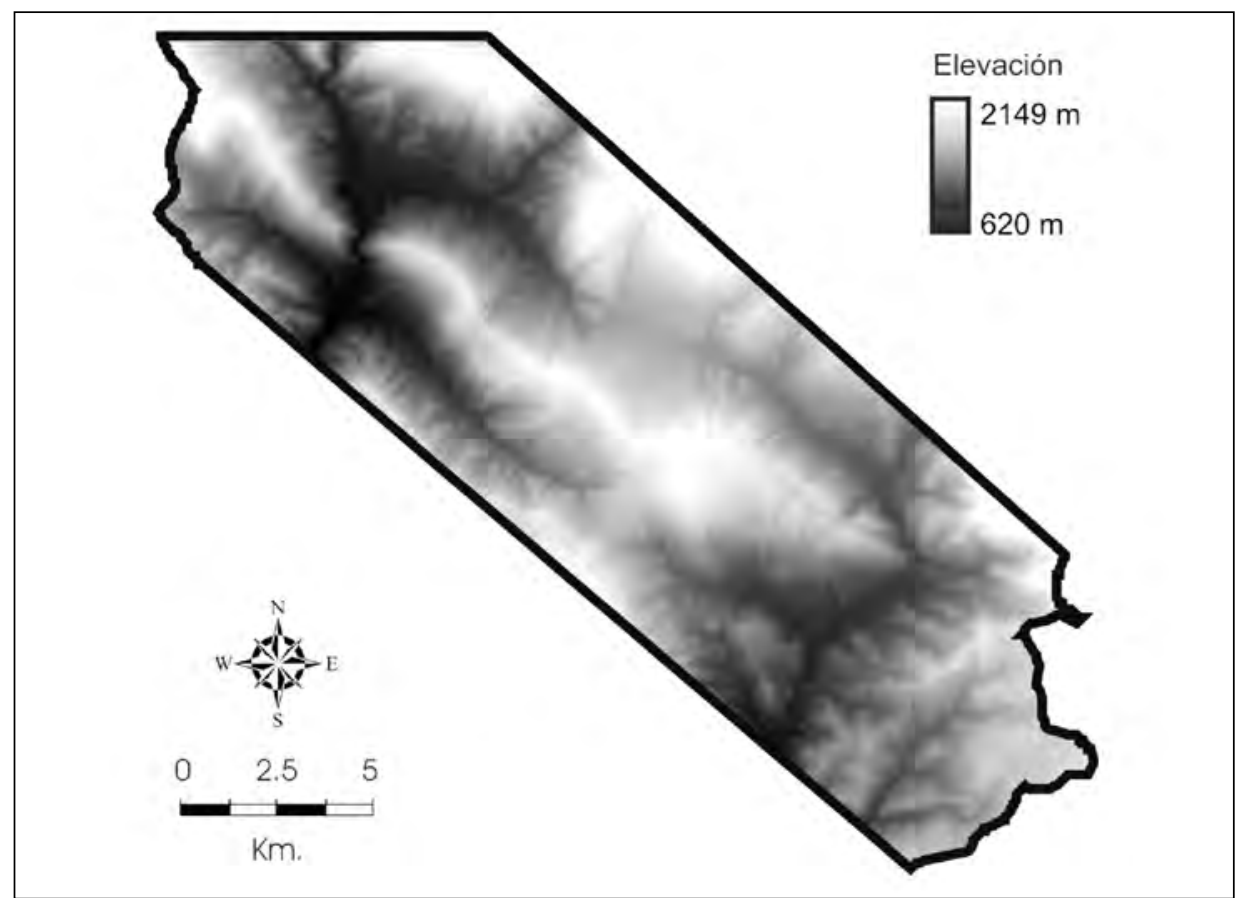

Figura 2. Modelo digital de elevaciones del área de estudio (MDT)

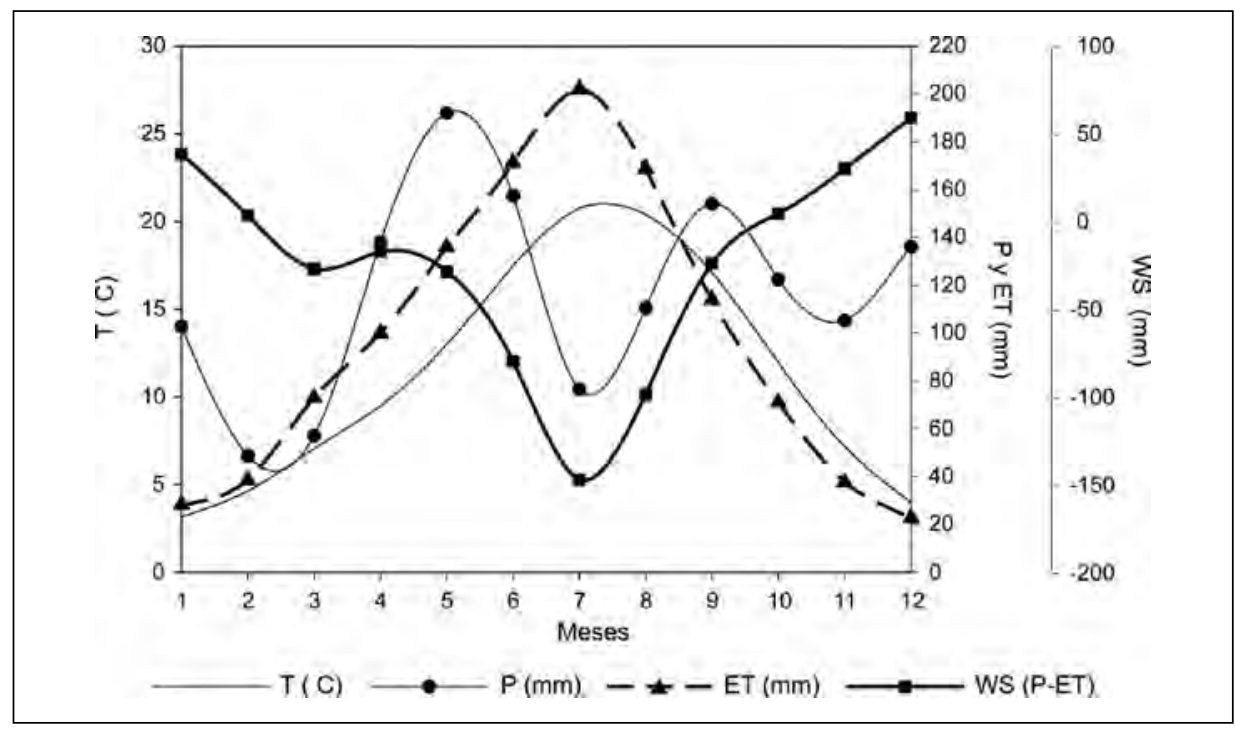

Figura 3. Diagrama ombroclimático de Campo, Huesca: T, temperatura media mensual en grados centígrados; , precipitación media mensual en milímetros; ET, evapotranspiración potencial en milímetros; WS, balance hídrico en milímetros $(P-E T)$ 


\section{Datos y metodología}

\subsection{Obtención y depuración de los datos de teledetección}

Una de las limitaciones que plantean las imágenes de satélite es que se encuentran afectadas por una serie de perturbaciones radiométricas: la iluminación solar y las condiciones atmosféricas, que dificultan su utilización. Este tipo de problemas se suelen solventar en las imágenes de baja resolución espacial y alta frecuencia temporal (p. ej., NOAA-AVHRR) mediante la creación de compuestos multitemporales y filtrados (Gutman et al., 1995). En el caso de las imágenes de alta resolución espacial, como las Landsat TM, en las que la frecuencia temporal es baja resulta necesario llevar a cabo procedimientos de corrección más complejos.

En este trabajo se ha utilizado una escena Landsat TM (resolución espacial de 30 m) tomada el mes de agosto de 2006, mes en que la disponibilidad resulta mayor por la menor frecuencia de cubierta nubosa (Fig. 1A). La imagen se corrigió geométricamente mediante puntos de control y el algoritmo desarrollado por Pala y Pons (1996) implementado en el software Miramon, en el que se tiene en cuenta la distorsión topográfica mediante la incorporación de un MDT.

El efecto atmosférico sobre la señal electromagnética ha sido corregido mediante el modelo de transferencia radiativa 6S (Vermote et al., 1997). Posteriormente, se corrigió el efecto que introducen las condiciones de iluminación para compensar las diferencias causadas por la irregularidad del terreno, para lo cual se ha utilizado un modelo de reflectividad anisotrópico o no lambertiano, ya que ofrece una mayor robustez que los modelos lambertianos (Riaño et al., 2003). Para una descripción más detallada del proceso de corrección radiométrica y geométrica de la imagen utilizada, ver Vicente-Serrano et al. (en revisión).

Finalmente, a partir de las imágenes corregidas atmosférica y topográficamente y normalizadas, se eliminaron las zonas afectadas por nubes mediante reconocimiento visual y se procedió a cortar la franja donde se localiza el corredor de afloramientos eocenos (Fig. 1B), para evitar confusiones con los diferentes ambientes del resto de la escena, quedando un área de estudio de $236 \mathrm{~km}^{2}$.

\subsection{Procedimiento de clasificación utilizado}

\section{Definición de las categorías temáticas y las áreas de entrenamiento}

En este apartado el objetivo es definir áreas de la imagen Landsat TM que representen las categorías temáticas presentes en la escena, con una máxima heterogeneidad espectral. Aunque el objetivo de este trabajo se centra en la identificación de áreas de erosión activa (cárcavas) y zonas de riesgo, para el correcto funcionamiento del algoritmo de clasificación es preciso establecer un conjunto de categorías que representen de 
forma adecuada la variabilidad de cubiertas presentes en el área de estudio. Ello es así porque el algoritmo de máxima verosimilitud tiene en cuenta no sólo las características medias de la signatura espectral de cada categoría, sino también la covarianza existente entre categorías.

La definición de las categorías temáticas de la escena, así como la selección de áreas de entrenamiento para cada categoría, se realizaron con la ayuda de ortofotos aéreas (SIGPAC, 2003). Para determinar el grado de discriminación entre las categorías, se utilizó la signatura espectral y una matriz de contingencia generada mediante el Software Erdas 8.7.

\section{Clasificación de la imagen y validación}

La clasificación de la imagen se realizó mediante el método de máxima verosimilitud (ingl. maximum likelihood) a partir del conjunto de categorías temáticas. La capacidad discriminatoria del modelo de clasificación se determinó mediante la matriz de confusión sobre la propia muestra de entrenamiento. Tras comprobar la adecuación de la muestra de entrenamiento se obtuvo un mapa de distancia espectral a la categoría de cárcavas. Esté mapa representa la distancia euclidiana entre la reflectividad de cada pixel y la signatura de la categoría de cárcavas. Los valores de reflectividad fueron reescalados a ocho bits, por lo que las unidades del mapa de distancia son unidades digitales con un rango entre 0 y 255. A partir del mapa de distancia espectral se confeccionaron los mapas de zonas de erosión activa (cárcavas) y zonas de riesgo mediante la determinación de sendos umbrales de clasificación. Para la confección de las curvas ROC, así como para la obtención de estadísticos de validación de la clasificación final, se utilizó una muestra independiente de 150 puntos distribuidos de forma aleatoria simple sobre el área de estudio, los cuales fueron clasificados mediante la ayuda de ortofotos aéreas (SIGPAC, 2003).

La determinación de los umbrales de clasificación para la confección de los mapas de zonas de erosión activa o cárcavas y las zonas de riesgo se basó en la metodología de la curva ROC (Beguería, 2006). La curva ROC se construye calculando, para cada valor de umbral de clasificación posible, los estadísticos de sensibilidad y especificidad de la clasificación resultante:

$$
\begin{aligned}
& \text { sensibilidad }=\frac{a}{a+c} \\
& \text { especificidad }=\frac{d}{b+d}
\end{aligned}
$$

donde: $a$ son los verdaderos positivos, $b$ verdaderos negativos, $c$ falsos positivo $y d$ los falsos negativos. 
La sensibilidad del modelo expresa la proporción de píxeles positivos correctamente predichos, o la probabilidad de que un píxel perteneciente a una categoría sea correctamente clasificado por el modelo. La especificidad del modelo es la proporción de píxeles negativos correctamente predichos, o la probabilidad de que un píxel no perteneciente a una categoría sea correctamente predicho por el modelo. Así, modelos con una elevada sensibilidad se caracterizan por una buena capacidad de clasificar correctamente los píxeles positivos o pertenecientes a la categoría de interés. Por contra, modelos con una elevada especificidad son aquellos con una buena capacidad para clasificar correctamente los píxeles negativos, o no pertenecientes a la categoría de interés. Generalmente una elevada sensibilidad conlleva una escasa especificidad, manifestada como una sobreestimación de las áreas pertenecientes a la categoría de interés. Los estadísticos de sensibilidad y especificidad proporcionan información sobre el grado de incertidumbre de la clasificación. Concretamente, los valores 1 -sensibilidad y 1-especificidad representan las probabilidades de cometer un error de omisión (error de tipo II, o falso negativo) y de comisión (error de tipo I, o falso positivo), respectivamente (Tabla 1). Otros estadísticos comunes de bondad del modelo de clasificación, como la fiabilidad global, son estimadores sesgados que dependen de la proporción de píxeles pertenecientes a cada categoría en la realidad, y por tanto no deben ser utilizados para la comparación entre distintos casos de estudio. La fiabilidad global se define mediante la siguiente expresión:

$$
\text { fiabilidad }=\frac{a+d}{a+b+c+d}
$$

El método de la curva ROC permite conocer el grado de incertidumbre asociado a un umbral de clasificación concreto. Para la determinación de las áreas de erosión activa (cárcavas) se fijó un valor del umbral de clasificación igual a la distancia espectral para la cual la sensibilidad del modelo fuera de 0.9 , correspondiente a una probabilidad de error de omisión del 10\%. Para la determinación de las áreas de riesgo de erosión se fijó un valor del umbral de clasificación igual a la distancia espectral para la cual la especificidad y sensibilidad del modelo fueran aproximadamente iguales.

Tabla 1. Matriz de confusión, mostrando los elementos necesarios para el cálculo de los estadísticos de la curva ROC. $Y_{1}$, perteneciente a la categoría $Y ; Y_{0}$, no perteneciente

a la categoría $Y$. Los valores a y d son los verdaderos positivos y verdaderos negativos, respectivamente. Los valores b y c son los falsos positivos y los falsos negativos, o errores de tipo I y de tipo II, respectivamente

\begin{tabular}{|l|c|c|c|}
\hline \multicolumn{2}{|c|}{} & \multicolumn{2}{|c|}{ Observados } \\
\cline { 3 - 4 } \multicolumn{2}{|c|}{} & $Y_{1}$ & $Y_{0}$ \\
\hline \multirow{2}{*}{ Predichos } & $Y_{1}{ }_{1}$ & $a$ & $b$ \\
& $Y^{\prime}{ }_{0}$ & $c$ & $d$ \\
\hline
\end{tabular}




\subsection{Caracterización topográfica de las áreas de cárcavas y de riesgo}

Finalmente se analizaron las características topográficas de las áreas clasificadas como cárcavas y como zonas de riesgo de erosión. Para ello se derivó la pendiente y la orientación de la ladera a partir del MDT, y se comparó estadísticamente la varianza de estas propiedades entre las dos categorías y el conjunto del área de estudio.

\section{Resultados y discusión}

\subsection{Selección de las categorías y de las áreas de entrenamiento}

La definición del conjunto de categorías temáticas y la selección de áreas de entrenamiento se realizó mediante la interpretación de ortofotos aéreas (SIGPAC, 2003). Se consideró que la variabilidad temática del área de estudio resultaba convenientemente representada mediante un conjunto de cinco categorías: áreas de erosión activa (cárcavas), matorral, pastizal, bosque de coníferas y bosque de frondosas. La selección de áreas de entrenamiento permitió obtener las signaturas espectrales para cada una de las categorías temáticas (Fig. 4). La categoría de cárcavas se caracteriza por presentar valores elevados de brillo en todas las bandas y por una mayor variabilidad espectral, características que son comunes a las zonas de suelo desnudo.

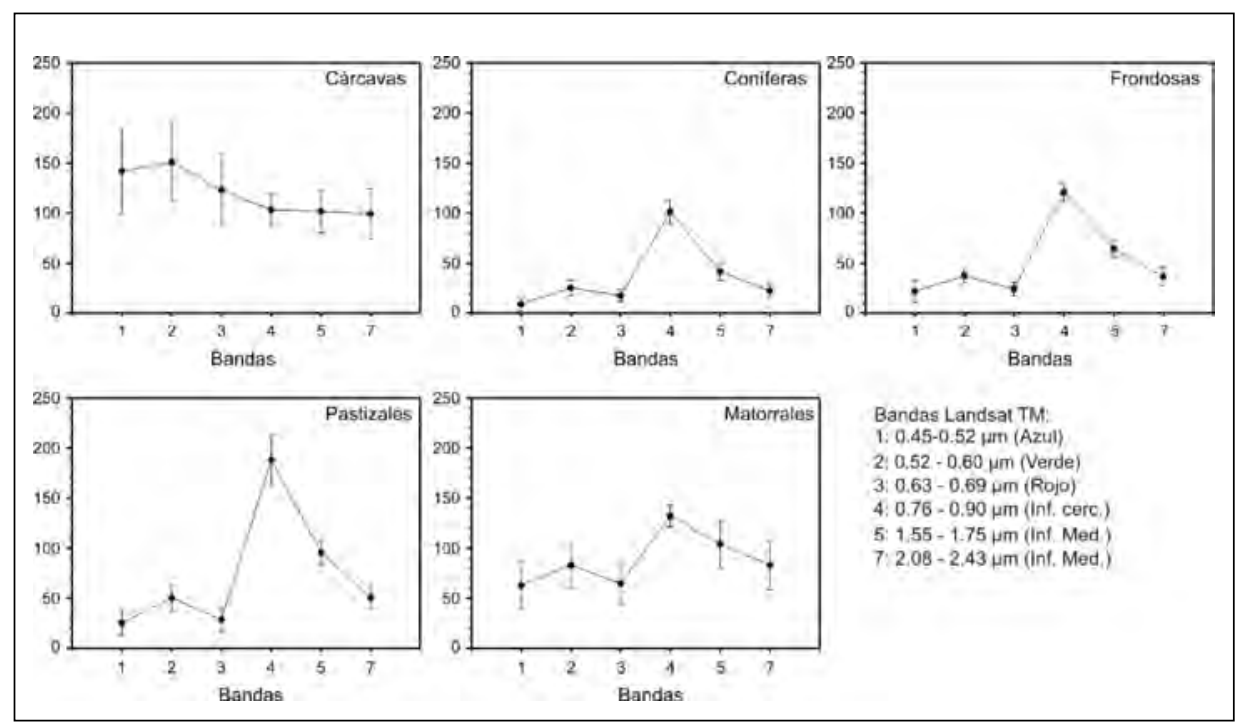

Figura 4. Curvas de brillo (signatura espectral) para cada una de las categorías temáticas en las seis bandas del satélite Lansat TM. Las barras verticales indican la desviación estándar en torno a la media de reflectividad (unidades digitales) 
La discriminación entre las distintas signaturas espectrales es buena, salvo en el caso de la banda 5 (infrarrojo medio de onda corta, SWIR), en la que los valores de reflectividad media de cárcavas, matorral y pastizal son muy similares. Dado que la banda 5 de Landsat TM responde a la variación en la humedad del suelo y la biomasa vegetal (Chuvieco, 1996), se puede deducir que las categorías de cárcavas, matorral y en menor grado el pastizal, presentan similares condiciones de humedad y actividad vegetal en la imagen de agosto. En zonas acarcavadas de clima subhúmedo la falta o escasez de vegetación se debe a la dificultad de colonizar unas laderas muy inestables, como consecuencia de un fuerte dinamismo geomorfológico la mayor parte del año (Solé et al., 1997). En el caso del Pirineo aragonés la distribución del matorral es difusa como consecuencia de las diferencias espaciales en las tasas de sucesión vegetal que se han venido presentando en las últimas décadas (Vicente-Serrano, 2006). La colonización vegetal de las zonas de suelo desnudo requiere de cada vez más tiempo, dando como resultado zonas de matorral con muy baja cobertura vegetal (Pueyo \& Beguería, 2007). La evolución de la cubierta vegetal en el Pirineo Central entre 1990 y 2000 se ha caracterizado por la estabilidad, ya que sólo el 0,9\% de la superficie muestra un proceso de matorralización (Vicente-Serrano et al., 2006).

La matriz de contingencia obtenida mediante la aplicación del algoritmo de clasificación de máxima verosimilitud a la muestra de entrenamiento indica que todas las categorías presentan porcentajes de acierto superiores al 90\% (Tabla 2). En el caso de las cárcavas, se obtuvo una confusión del $1 \%$ con la categoría de matorral, confirmando lo anteriormente mencionado sobre las zonas de transición. En primera instancia, este resultado indica que la clasificación resultante sería muy consistente.

Tabla 2. Matriz de contingencia de la clasificación aplicada a la muestra de entrenamiento (proporción y número de píxeles totales)

\begin{tabular}{|c|c|c|c|c|c|c|c|}
\hline & $\begin{array}{l}\text { Categorías } \\
\text { observadas }\end{array}$ & Cárcavas & Coníferas & Frondosas & Pastizales & Matorral & $\begin{array}{l}\text { Total fila } \\
\text { (píxeles) }\end{array}$ \\
\hline \multirow{6}{*}{ 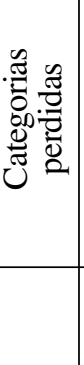 } & Cárcavas & 0.99 & 0 & 0 & 0 & 0.01 & 832 \\
\hline & Coníferas & 0 & 0.94 & 0.01 & 0 & 0 & 1098 \\
\hline & Frondosas & 0 & 0.04 & 0.95 & 0 & 0.02 & 308 \\
\hline & Pastizales & 0 & 0 & 0 & 0.99 & 0 & 300 \\
\hline & Matorral & 0.01 & 0.02 & 0.04 & 0.01 & 0.97 & 1151 \\
\hline & $\begin{array}{l}\text { Total columna } \\
\text { (píxeles) }\end{array}$ & 835 & 1164 & 247 & 298 & 1145 & 3689 \\
\hline
\end{tabular}




\subsection{Clasificación temática de la imagen}

Como resultado intermedio del algoritmo de clasificación se obtuvo un mapa de cubierta del suelo (Fig. 5). La validación con una muestra aleatoria independiente arrojó unos valores de fiabilidad global del $81.83 \%$. La mayor confusión se dio en la categoría de pastizales, con un error de comisión del $25.76 \%$ y error de omisión del $14.04 \%$ (sensibilidad $=0.860$, especificidad $=0.742)$ (Tabla 3 ). La categoría de frondosas fue la que mejor se discriminó del resto, con un error de comisión del 6.25\%. El modelo de clasificación fue muy sensible con respecto a la categoría de cárcavas, presentando una probabilidad de error de omisión de $12.90 \%$ (sensibilidad = 0.871). Sin embargo, la clasificación de las cárcavas se resintió por la confusión de algunas áreas de matorral que fueron clasificadas incorrectamente, resultando en un error de comisión del $22.86 \%$ (especificidad $=0.771$ ).

La distribución espacial del área ocupada por cada categoría es: cárcavas $19 \mathrm{~km}^{2}$, coníferas $65 \mathrm{~km}^{2}$, frondosas $21 \mathrm{~km}^{2}$, pastizales $32 \mathrm{~km}^{2}$, matorrales $99 \mathrm{~km}^{2}$. Se observa que las áreas ocupadas por matorral y pastizal se localizan bordeando las zonas clasificadas como cárcavas (Fig. 6). Esta distribución espacial sugiere que existe una transición progresiva entre las áreas erosionadas y el bosque.

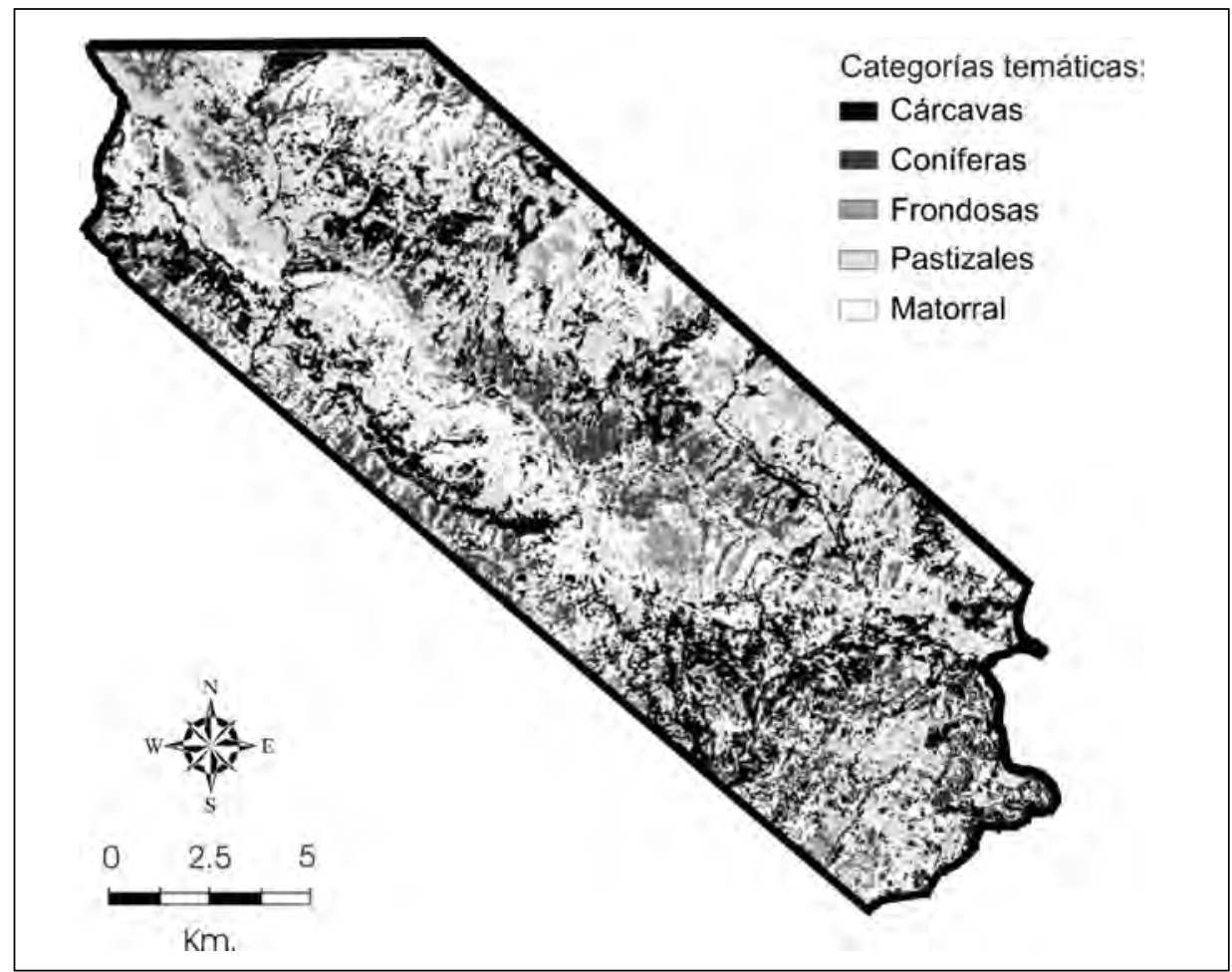

Figura 5. Mapa de cubierta del suelo obtenido mediante el procedimiento de clasificación supervisada por el método máxima verosimilitud 


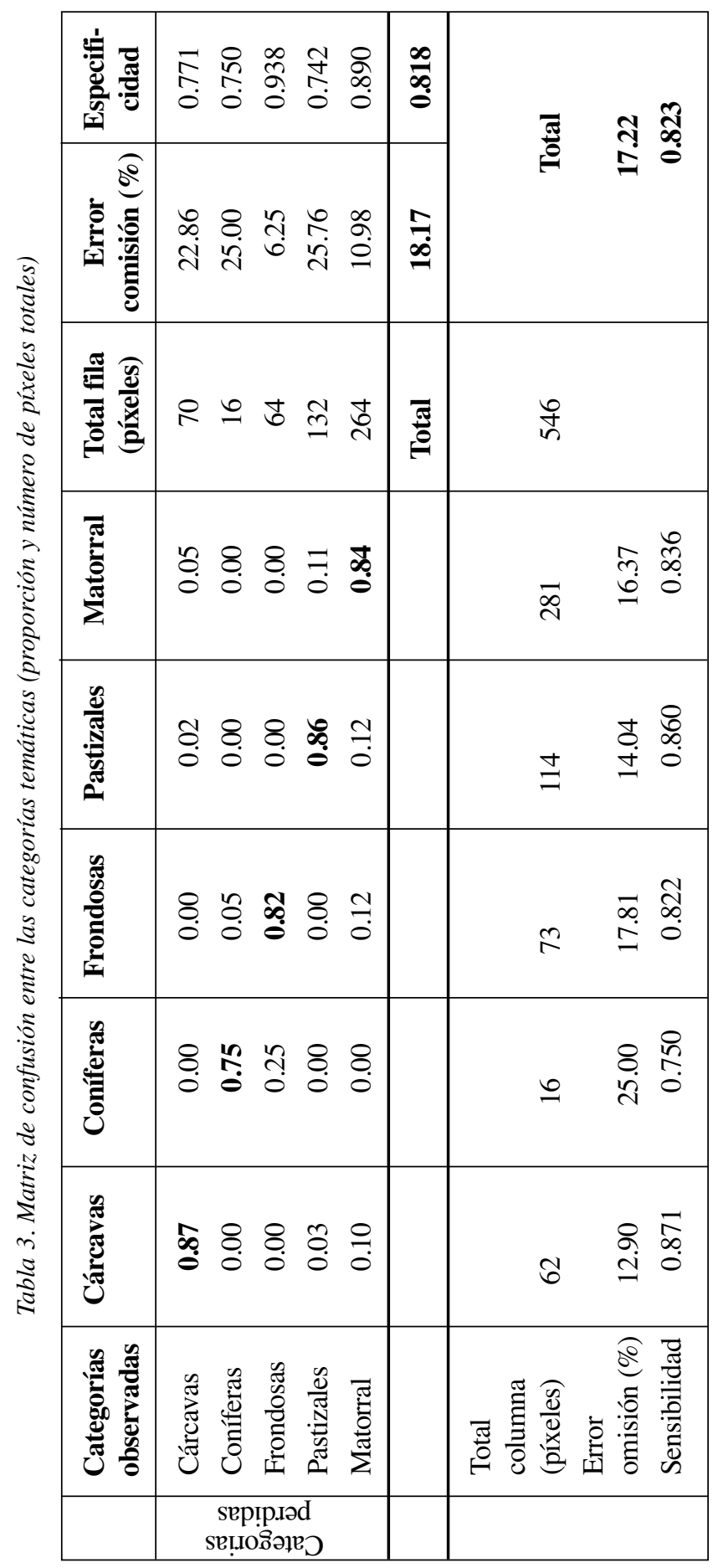




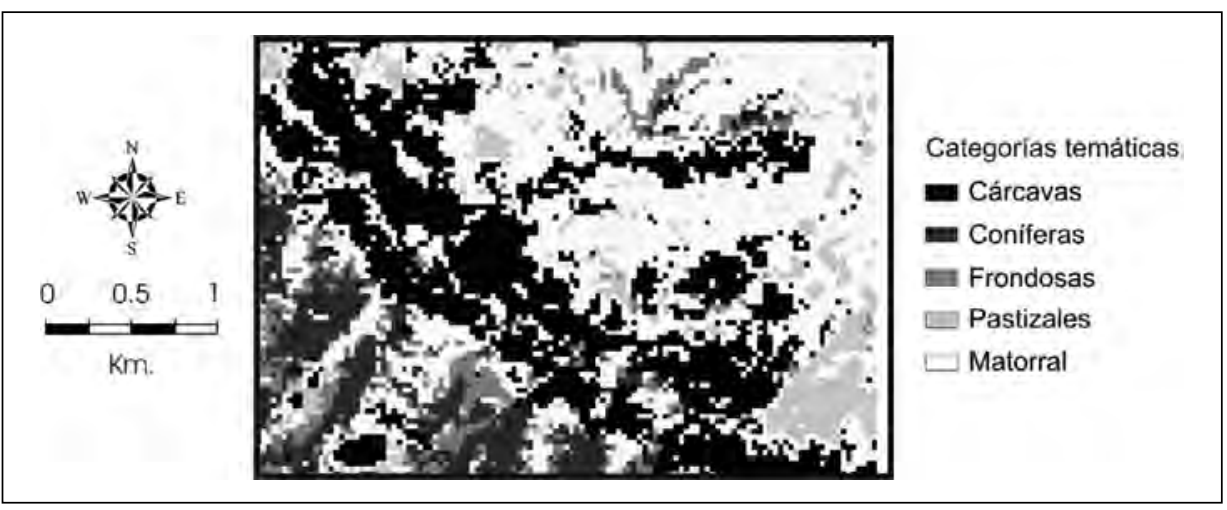

Figura 6. Detalle de las zonas de transición entre las cárcavas y bosque (coníferas y frondosas)

\subsection{Mapa de cárcavas y zonas de riesgo}

Una vez validado el procedimiento de clasificación de la imagen, para la obtención del mapa de cárcavas y zonas de riesgo se utilizó únicamente el mapa de distancia espectral a la categoría de cárcavas, generada conjuntamente con la clasificación (Fig. 7). El mapa de distancia espectral es un requisito intermedio en el procedimiento de clasificación supervisada, que lo utiliza para asignar cada píxel a la categoría temática de mayor similitud (menor distancia espectral). Sin embargo, cuando el interés se centra en una de las cubiertas, como es el caso de este trabajo, es posible obtener una clasificación mucho más precisa utilizando el mapa de distancia espectral generado y aplicando un valor de umbral de clasificación determinado por el usuario. Si bien es posible obtener un mapa de distancia espectral a la categoría de cárcavas a partir únicamente de una muestra de píxeles de dicha categoría, la inclusión de signaturas espectrales de otras cubiertas presentes en el área de estudio permite obtener una estimación mucho más precisa, teniendo en cuenta la matriz de varianzas / covarianzas entre las distintas signaturas.

La curva ROC construida para la categoría de cárcavas mostró una capacidad discriminatoria de tipo medio a alto (Fig. 8). La curva ROC muestra los valores de sensibilidad y especificidad asociados a distintos valores posibles del umbral de clasificación. Como se puede observar, la determinación del umbral de clasificación requiere llegar a un compromiso entre las dos características, puesto que resulta imposible maximizar ambas a un mismo tiempo. Así, la opción por un modelo con una elevada sensibilidad (es decir, con un error de omisión muy bajo) conlleva de forma asociada valores mediocres de especificidad, resultando por tanto en una sobreestimación de las áreas pertenecientes a la categoría de cárcavas.

En el caso que nos ocupa se optó por un modelo con una elevada especificidad (0.900), de manera que se minimizara el error de comisión o de falso positivo. Se trata éste de un criterio clásico en análisis estadístico, equivalente a la elección de un nivel de confianza de $\alpha=0.1$. Para la delimitación de las áreas de riesgo de erosión se buscó el 


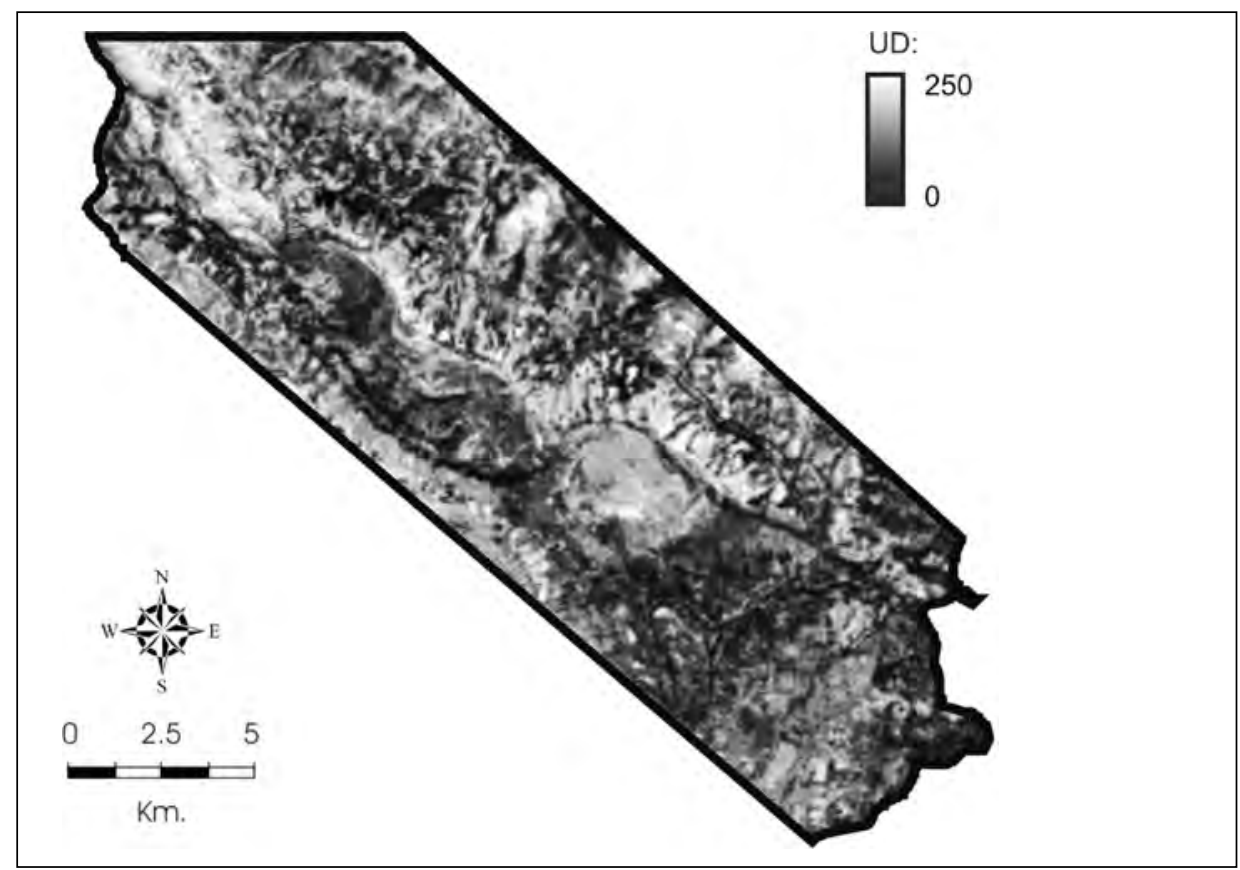

Figura 7. Mapa de distancia espectral (UD: unidades digitales) a la categoría de cárcavas, considerando las signaturas espectrales de las demás categorías

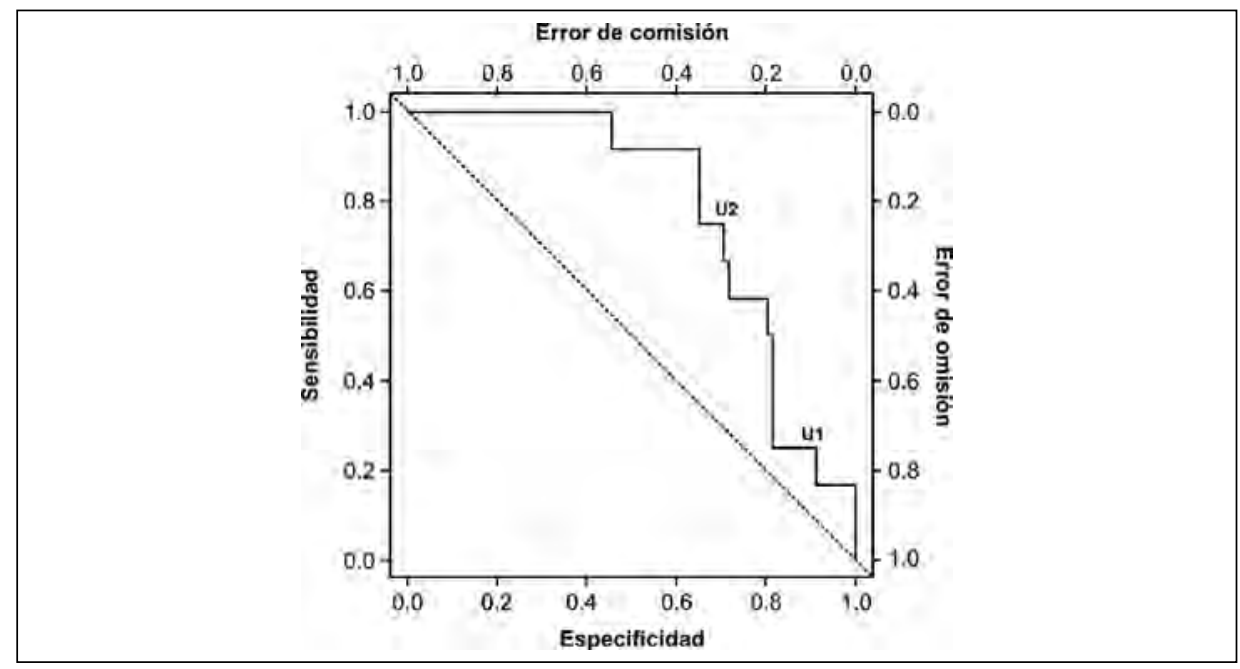

Figura 8. Curva ROC para la clasificación de la categoría de áreas de erosión activa (cárcavas). La línea de trazos central indica como referencia la curva ROC correspondiente a un modelo aleatorio sin capacidad predictiva. Por tanto, cuanto más alejada se encuentra la curva ROC de la línea central tanto mejor será la capacidad discriminatoria del modelo. Las etiquetas U1 y U2 indican los umbrales de clasificación elegidos para la confección del mapa de áreas de erosión activa y zonas de riesgo 
valor del umbral de clasificación que resultara en valores aproximadamente iguales de sensibilidad y especificidad. Éstos se determinaron en 0.750 y 0.710 , respectivamente.

La aplicación de los dos umbrales de clasificación al mapa de distancia espectral a la categoría de cárcavas dio como resultado el mapa de zonas de erosión activa y áreas de riesgo (Fig. 9). La superficie ocupada por cada una de éstas es de $17 \mathrm{~km}^{2}$ y $49 \mathrm{~km}^{2}$, respectivamente. La superficie de las áreas de erosión activa es prácticamente idéntica a la de la categoría de cárcavas del mapa de cubierta de suelo generado anteriormente. La comparación visual entre ambos mapas muestra que las zonas clasificadas como de riesgo se corresponden en su mayoría con zonas de matorral (en algunos casos pastizal o coníferas) aledañas a las zonas de cárcavas. Dichas zonas presentan características espectrales intermedias entre las categorías mencionadas, indicando ya sea una mezcla de las categorías dentro del píxel o bien una situación intermedia de degradación. Ambas posibilidades concuerdan con la clasificación de dichas áreas como zonas de riesgo de erosión.

El análisis morfológico a partir del MDT muestra un predominio de las orientaciones norte (33\%) y sur (45\%) para la totalidad de la zona de estudio (Fig. 10A). Por el contrario, las zonas de cárcavas presentan una mayor presencia en laderas con orientación norte $(44 \%)$, mientras que las zonas de riesgo presentan una distribución similar a la del área total (Fig. 10, C y B). La disposición de las zonas de cárcavas de forma marcada-

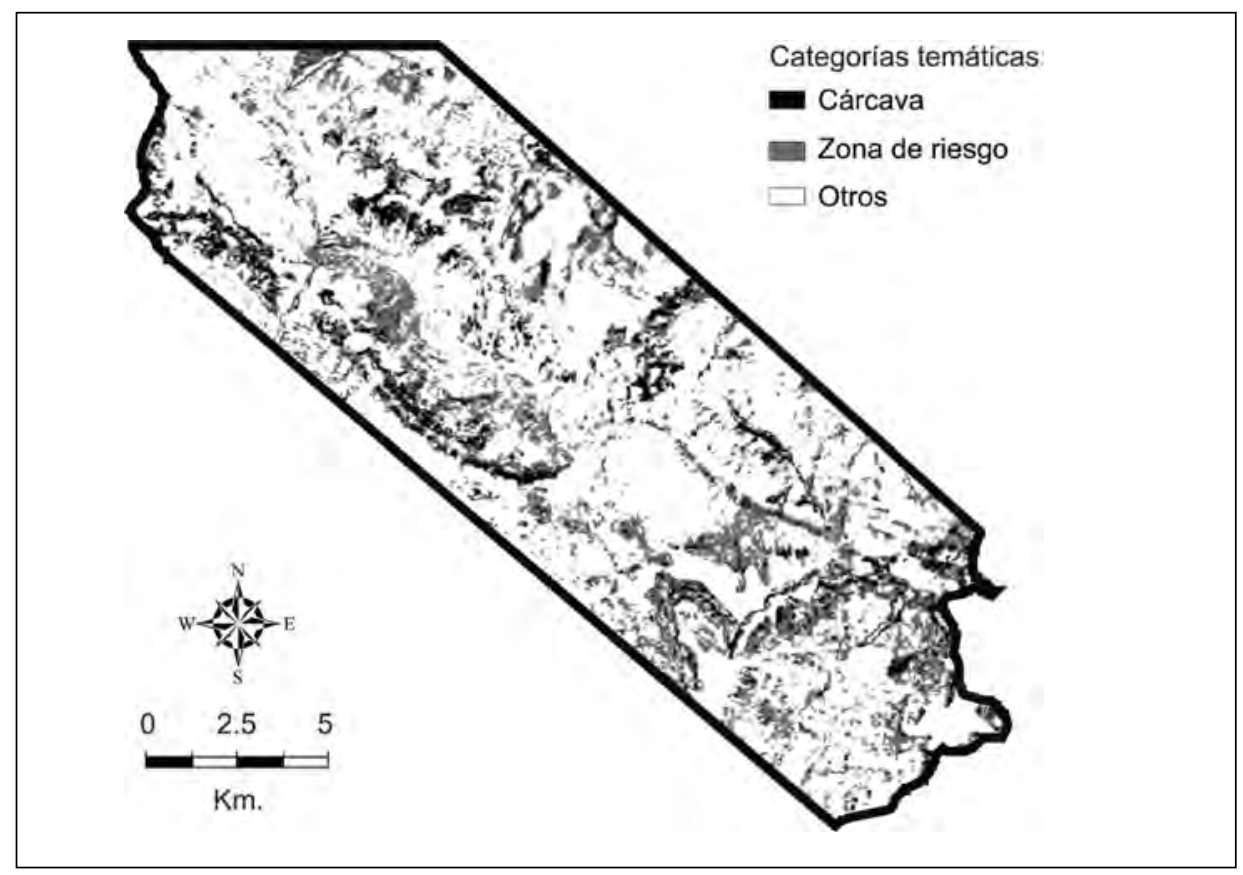

Figura 9. Mapa de áreas de erosión activa (cárcavas) y zonas de riesgo, obtenido a partir del mapa de distancia espectral y la selección del umbral de clasificación a partir de la curva ROC 


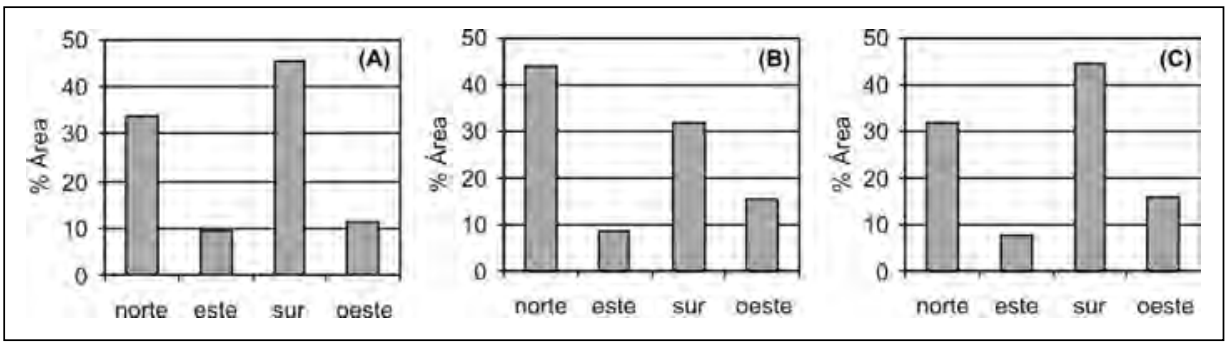

Figura 10. Distribución porcentual de la orientación: A, área total; B, zonas de cárcavas; $C$, zonas de riesgo

mente diferente a la del resto del área de estudio sugiere la existencia de procesos diferenciales de erosión en función de la exposición de la ladera. La exposición de la vertiente es un factor determinante en la dinámica, en la intensidad y en la eficacia de los procesos de meteorización en áreas acarcavadas, desarrolladas en zonas de montaña subhúmedas (Nadal-Romero et al., 2007). Ello se debe a la meteorización más rápida de la roca en regolito por acción de los agentes climáticos, fundamentalmente de los ciclos de hielo y deshielo, en las laderas con orientación norte. En las laderas con orientación sur en cambio, predominan los procesos de humectación-secado, asociados al encostramiento y compactación del regolito. La constatación de este hecho permitiría la limitación de las áreas consideradas de riesgo de erosión a aquellas que presentaran una exposición norte.

También se analizó la distribución de frecuencias de las pendientes en cada una de las categorías (Fig. 11), encontrándose que no existen diferencias significativas entre las zonas con cárcavas y las zonas de riesgo y el área total.

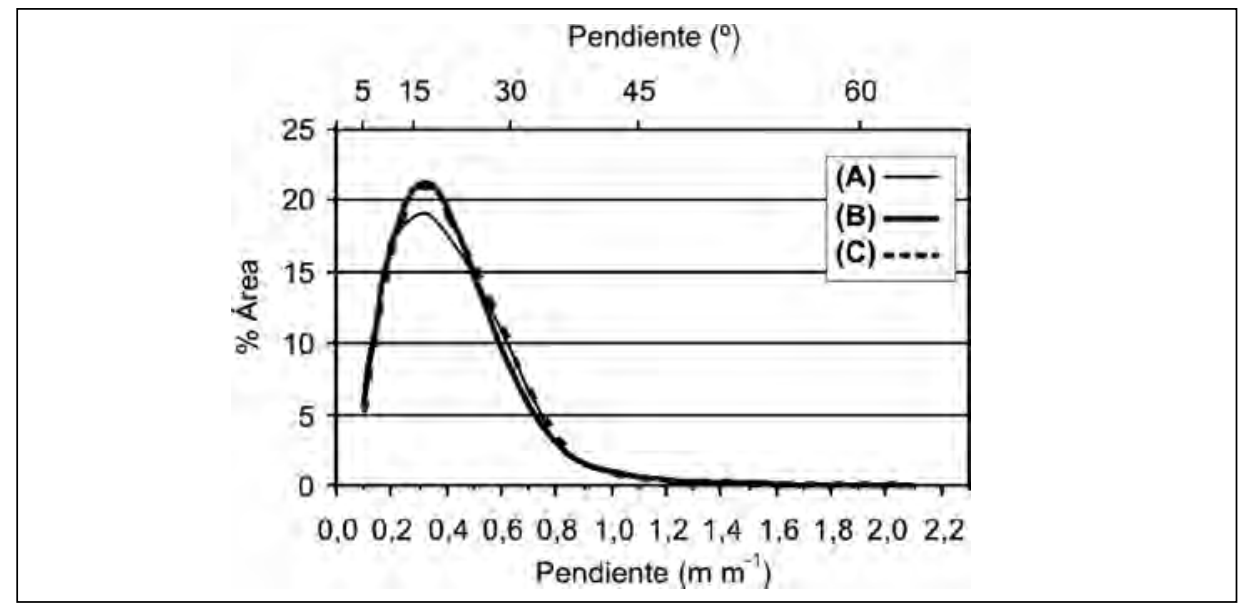

Figura 11. Histograma de frecuencias de la pendiente: A, área total; $B$, zona de cárcavas; $C$, zona de riesgo 


\section{Conclusiones}

El presente trabajo muestra la utilidad de las técnicas de teledetección y SIG en la investigación geomorfológica básica y aplicada, a escalas de cuenca y regional (áreas de estudio entre los 10 y los $10,000 \mathrm{~km}^{2}$ ). Con respecto a la utilización de la teledetección en áreas de montaña, se ha puesto de manifiesto la gran importancia de la fase de preproceso de las imágenes, más crítica si cabe que en las zonas de menor relieve. Es precisamente el fuerte relieve la causa de importantes distorsiones geométricas en las áreas de montaña, además de introducir severos problemas de iluminación. En una fase preliminar de la investigación (cuyos resultados no se muestran en este trabajo, VicenteSerrano et al., en revisión) se ha podido comprobar que la utilización de un procedimiento de corrección no lambertiano basado en la reflexión bidireccional (modelo de Minnaert) supone una importante mejora sobre las imágenes corregidas con el procedimiento unidireccional o lambertiano más común.

La utilización de técnicas de clasificación supervisada mediante el método de máxima verosimilitud a partir de un conjunto a priori de categorías (cubiertas), ha permitido obtener una cartografía de áreas de erosión activa (cárcavas) y de vegetación, con un nivel de fiabilidad del $82 \%$. Sin olvidar que la correcta selección de áreas de entrenamiento con la ayuda de ortofotos aéreas (SIGPAC, 2003) ha permitido localizar áreas para cada una de las categorías (réplicas), dando como resultado una máxima variabilidad posible de las signaturas espectrales entre las mismas.

La utilización de la curva ROC, que evalúa la incertidumbre del modelo de clasificación a partir de la magnitud de los errores de omisión y comisión, permitió determinar los umbrales de clasificación para las áreas de erosión activa y zonas de riesgo. Se ha comprobado que el $7 \%$ de la superficie del área de estudio se encuentra afectado por procesos de erosión activa que dan lugar a morfologías de cárcavas. El 21\% de la superficie es clasificada como zonas de riesgo. Se trata siempre de píxeles próximos a las zonas de cárcavas y que presentan un grado elevado de confusión espectral entre la categoría de cárcavas y otras categorías. Se trata de zonas de riesgo de degradación, ya sea por intensificación de los procesos de erosión o por la acción remontante de las cabeceras de las cárcavas próximas. Las zonas de riesgo se localizan bordeando las zonas de cárcavas, coincidiendo con las zonas de transición entre las cárcavas y el bosque, en donde el suelo se encuentra deficientemente recubierto por vegetación (10-50\% de cobertura). Al ser áreas marginales el establecimiento de la vegetación es difícil, donde la mayor parte se encuentra con pendientes mayores a $15 \%$.

Finalmente queda patente que la utilización de un MDT para hacer una exploración morfológica de las áreas con erosión activa y zonas de riesgo es una herramienta útil como primer acercamiento. En el área de estudio, se pudo deducir una asimetría en el desarrollo de las áreas acarcavadas en función de la orientación. Concretamente, se ha detectado un mayor desarrollo de las cárcavas en las vertientes umbrías, como efecto de una mayor acción de los procesos de meteorización. La pendiente de la ladera, por el contrario, no parece tener un efecto significativo sobre la formación de cárcavas en el área analizada. 


\section{Agradecimientos}

Este trabajo no habría sido posible sin la ayuda del Dr. Sergio Vicente Serrano, quien amablemente proporcionó la imagen Landsat TM utilizada, corregida radiométrica y geométricamente. La investigación realizada se enmarca dentro del proyecto "Procesos y Balances Hidrológicos y de Sedimentos a Diferentes Escalas Espaciales en Ambientes Mediterráneos: Efectos de las Fluctuaciones Climáticas y los Cambios de Uso del Suelo-PROBASE" (CONSOLIDER, CGL2006-11619/HID). La contribución del primer autor ha sido posible gracias a la beca predoctoral otorgada por el Consejo Nacional de Ciencia y Tecnología de México (CONACYT).

\section{Referencias bibliográficas}

BegueríA, S. (2005). Identificación y Características de las Fuentes de Sedimento en Áreas de Montaña: Erosión y Transferencia de Sedimento en la Cuenca Alta del Río Aragón. Instituto Pirenaico de Ecología, Zaragoza.

BEGUERÍA, S. (2006). Identifying erosion areas at basin scale using remote sensing data and GIS. International Journal of Remote Sensing, 20: 4585-4598.

BraZIER, R.E., BEVEN, K.J., FrEer J.F., RowAN, J.S. (2000). Equifinality and uncertainty in physically based soil erosion models: application of the GLUE methodology to WEPP (the Water Erosion Prediction Project) for sites in the UK and USA. Earth Surface Processes and Landforms, 25: 825-845.

BRYAN, R., YAIR, A. (1982). Perspectives on studies of badland geomorphology. In: Badland Geomorphology and Piping (Bryan, R., Yair, A., Eds.). Geobooks, pp. 1-12, Norwich.

CAMPBell, I.A. (1989). Badlands and badland gullies. In: Arid Zone Geomorphology (Thomas, D.S.G., Ed.). Belhaven, pp. 159-183, London.

Chuvieco, E. (1996). Fundamentos de teledetección espacial. Ediciones RIALP, S.A. Madrid, España, Segunda edición, 451 pp.

DE JONG, S.M. (1994). Applications of Reflective Remote Sensing for Land Degradation Studies in a Mediterranean environment. PhD Dissertation Thesis, Nederlandse Geografische Studies 177, Utrecht, The Netherlands, 179 pp.

Fargas, D., Martínez-Casasnovas, J.A., Poch, R.M. (1997). Identification of critical sediment source areas at regional level. Physics and Chemistry of the Earth, 22: 355-359.

FLORAS, S.A., SGOURAS, I.D. (1999). Use of geoinformation techniques in identifying and mapping areas of erosion in a hilly landscape of central Greece. International Journal of Applied Earth Observation and Geinformation, 1: 68-77. 
FRAZIER, B.E., CHENG, Y. (1989). Remote sensing of soils in the eastern Palouse region with Landsat Thematic Mapper. Remote Sensing of Environment, 28: 317-325.

GAllart, F., LloRENS, P., LATRON, J., REGÜÉS, D. (2002). Hydrological processes and their seasonal controls in a small Mediterranean mountain catchment in the Pyrenees. Hydrology and Earth System Sciences, 6(3): 527-537.

García Ruiz, J.M., Puigdefábregas, J., Creus, J. (1985). Recursos hídricos Superficiales del Alto Aragón. Instituto de Estudios Altoaragoneses, 224 pp., Huesca.

García-MeléndeZ, E., MolinA, I, Ferré-Juliá, M., Aguimet, J. (1998). Multisensor data integration and GIS analysis for natural hazard mapping in a semiarid area (Southeast Spain). Advanced Space Research, 21: 493-499.

Giannetti, F., Montanarella, L., Salandin, R. (2001). Integrated use of satellite images, DEMs, soil and substrate data in studying mountainous lands. International Journal of Applied Earth Observation and Geoinformation, 3: 25-29.

Gutman, G.,TARPley, D., IgnAtov, A., Olson, S. (1995). The enhanced NOAA global land dataset from the advanced very high resolution radiometer. Bulletin of the American Meteorological Society. 76: 1141-1156.

Haboudane, D., Bonn, F., Royer, A., Sommer, S., Mehl, W. (2002). Land degradation and erosion risk mapping by fusion of spectrally based information and digital geomorphometric attributes. International Journal of Remote Sensing, 18: 37953820 .

Jetten, V., De Roo, A., FAvis-Mortlock, D. (1999). Evaluation of field-scale and catchment-scale soil erosion models. Catena, 37: 521-541.

JETTEN, V., GOVERS, G., HeSSEL, R. (2003). Erosion models: quality of spatial predictions. Hydrological Processes, 17: 887-900.

Kirkby, M.J., Imeson, A.C., BergKamp, G., CAmmeraAt, L.H. (1996). Scaling up processes and models from the field plot to the watershed and regional areas. Journal of Soil and Water Conservation, 51: 391-396.

KoCH, M. (2000). Geological controls of land degradation as detected by remote sensing: a case study in Los Monegros, north-east Spain. International Journal of Remote Sensing, 21: 457-473.

KoOpMAns, B.N., Forero, R.G. (1993). Airborne SAR and Landsat MSS as complementary information source for geological hazard mapping. ISPRS Journal of Photogrammetry and Remote Sensing, 48: 28-37.

LAmbin, E.F. (1996). Change Detection at Multiple Temporal Scales: Seasonal and Annual Variations in Landscape Variables. Photogrammetric Engineering and Remote Sensing, 62(8): 931-938. 
MA, J.W., XUE, Y., MA, C.F., WANG, Z.G. (2003). A data fusion approach for soil erosion monitoring in the Upper Yangtze River Basin of China based on Universal Soil Loss Equation (USLE) model. International Journal of Remote Sensing, 24: 47774789 .

MathieU, R., KInG, C., Bissonnais, Y. (1997). Contribution of multi-temporal SPOT data to the mapping of a soil erosion index: the case of the loamy plateaux of northern France. Soil Technology, 10(2): 99-110.

Mati, B.M., Morgan, R.P.C., Gichuki, F.N., Quinton, J.N., Brewer, T.R., Liniger, H.P. (2000). Assessment of erosion hazard with the USLE and GIS: a case study of the upper Ewaso Ng'iro North basin of Kenya. International Journal of Applied Earth Observation and Geoinformation, (2): 78-86.

MERRIT, W.S., LETCHER, R.A., JAKEMAN, A.J. (2003). A review of erosion and sediment transport models. Environmental Modelling \& Software, 18: 761-799.

MetTERnicht, G.I., FERMONT, A. (1998). Estimating erosion surface features by linear mixture modelling. Remote Sensing of Environment, 64: 254-265.

MeTterniCHT, G.I., ZINCK, J.A. (1998). Evaluating the information content of JERS-1 SAR and Landsat TM data for discrimination of soil erosion features. Photogrammetric Enginering and Remote Sensing, 53: 143-153.

METTERNICHT, G.I., GONZALEZ, S. (2005). FUERO: foundations of a fuzzy exploratory model for soil erosion hazard prediction. Environmental Modelling \& Software, 20: 715-728.

Millward, A.A., Mersey, J.E. (1999). Adapting the RUSLE to model soil erosion potential in a mountainous tropical watershed. Catena, 38(2): 109-129.

Morgan, P.C. (1997). Erosión y conservación del suelo. Ed. Mundi-Prensa, 343 pp. Madrid.

Muchoney, D., HAACK, B. (1994). Change Detection for Monitoring Forest Defoliation. Photogrammetric Engineering \& Remote Sensing, 60(10): 1243-1251.

Nadal-Romero, E., Regüés, D., Martí-Bono, C., Serrano-Muela, P. (2007). Badlands dynamics in the Central Pyrenees: temporal and spatial patterns of weathering processes. Earth Surfaces Processes and Landforms, 32(6): 888-904.

Oostwoud-Wijdenes, D.J., Poesen, J., Vandekerckhove, L., Ghesquiere, M. (2000). Spatial distribution of gully head activity and sediment supply along an ephemeral channel in a Mediterranean environment, Catena, 39: 147-167.

PALA, V., PONS, X. (1996). Incorporation of relief in polynomial-based geometric corrections. Photogrammetric engineering \& Remote Sensing, 61(7): 935-944. 
PARDINI, G. (1996). Evoluzione temporale della microtopografia superficiale, della micromorfologia e della struttura in relazione ai processi di meteorizzazione nelle marne smectitiche di Vallcebre. Ph.D. Dissertation. Universidad de Barcelona UB, Barcelona.

PARINGIT, E., NADAOKA, K. (2003). Sediment yield modelling for small agricultural catchments: Landcover parameterization based on remote sensing data analysis. Hydrological Processes, 17: 1845-1866.

PICKUP, G., NELSON, D.J. (1984). Use of Landsat radiance parameters to distinguish soil erosion, stability and deposition in arid central Australia. Remote Sensing of Environment, 16: 195-209.

PICKuP, G., ChewINGS, V.H. (1988). Forecasting patterns of soil erosion in arid lands from Landsat MSS data. International Journal of Remote Sensing, 9: 69-84.

PILESJO, P. (1992). GIS and Remote Sensing for Soil Erosion Studies in Semi-arid Environments. $\mathrm{PhD}$ thesis, Institutioner, Avhandlingar CXIV. Meddelanden fran Lunds Universitets Geografiska, Lunds, Sweeden, 203 pp.

PueYo, Y., BEGUERIA, S. (2007). Modelling the rate of secondary succession after farmland abandonment in a Mediterranean mountain area. Landscape and Urban Planning, 83(4): 245-254.

REGÜÉS, D. (1995). Meteorización física en relación con los procesos de producción y transporte de sedimentos en un área acarcavada. Ph.D. Dissertation. Universidad de Barcelona UB, Barcelona.

REgÜÉS, D., PARDINI, G., GAllaRT, F. (1995). Regolith behaviour and physical weathering of clayey mudrock as dependent on seasonal weather conditions in a badland area at Vallcebre, Eastern Pyrenees. Catena, 25(1-4): 199-212.

Reusing, M., SchneIder, T., AMmer, U. (2000). Modelling soil loss rates in the Ethiopian Highlands by integration of high resolution MOMS-02/D2-stereo-data in a GIS. International Journal of Remote Sensing, 21(9): 1885-1896.

Riaño, D., Chuvieco, E., Salas, J., Aguado, I. (2003).Assessment of different topographic corrections in Landsat TM data for mapping vegetation types. IEEE Transactions on Geoscience and Remote Sensing, 41(5): 1056-1061.

Rode, M., FREDE, H.G. (1997). Modification of AGNPS for agricultural land and climat condition in central Germany. J. of Environmental Quality, 26(1): 165-172.

SCHOORL, J.M., SONNEVELD, M.P.W., VELDKAMP, A. (2000). Three-dimensional landscape process modelling: the effect of DEM resolution. Earth Surface Processes and Landforms, 25: 1025-1034. 
Shrimali, S.S., AgGarwal, S.P., SAMra, J.S. (2001). Prioritizing erosionprone areas in hills using remote sensing and GIS - a case study of the Sukhna Lake sub-catchment, Northern India. International Journal of Applied Earth Observation and Geoinformation, 3: 54-60.

SIGPAC, (2003). Sistema de Información Geográfica de Parcelas Agrícolas de España. Ministerio de Agricultura, Pesca y Alimentación.

http://www.mapa.es/es/sig/pags/sigpac/intro.htm

Singh, D., Herlin, I., Berroir, J.P., Silva, E.F., Simoes-Meirelles, P. (2004). An approach to correlate NDVI with soil colour for erosion process using NOAA/AVHRR data. Advances in Space Research, 33(3): 328-332.

SinghroY, V. (1995). SAR integrated techniques for geohazard assessment. Advanced Space Research, 1: 67-78.

Singhroy, V., MATTAR, K.E., GRAY, A.L. (1998). Landslide characterisation in Canada using interferometric SAR and combined SAR and TM images. Advanced Space Research, 21: 465-476.

Solé, A., CAlvo, A., Cerdà, A., LÁZAro, R., Pini, R., BArbero, J. (1997). Influences of micro-relief patterns and plant cover on runoff related to processes in Badlands from Tabernas (SE Spain). Catena, 31: 28-38.

SyMEONAKIS, E., DRAKE, N. (2004). Monitoring desertification and land degradation over sub-Saharan Africa. International Journal of Remote Sensing, 25: 573-592.

SzABO, J., PASZTOR, Z., Suba, VARALlyay, G. (1998). Integration of remote sensing and GIS techniques in land degradation mapping. Proceeding of the $16^{\text {th }}$ International Congress of Soil Science, Montpellier, pp. 63-75, France.

TORRI, D., RODOLFI, G. (2000). Badlands in changing environments: an introduction. Catena, 40: 119-125.

TRIPATHY, G.K., GHOSH, T.K., SHAH, S.D. (1996). Monitoring of desertification process in Karanataka state of India using multi-temporal remote sensing and ancillary information using GIS. International Journal of Remote Sensing, 17: 2243-2257.

VAlero-GArcÉs. B.L., NAVAS, A., Machín, J., WALling, D. (1999). Sediment sources and siltation in mountain reservoirs: a case study from the central Spanish Pyrenees. Geomorphology, 28: 23-41.

Vermote, E.F., Tanré, D., Deuzé, J.L., Herman, M., Morcrette, J.J. (1997). Second simulation of the satellite signal in the solar spectrum, 6s: an overview. IEEE Transactions on Geoscience and Remote Sensing, 35(3): 675-686. 
Vicente-Serrano, S.M., Beguería, S., LASANTA, T. (2006). Diversidad espacial de la actividad vegetal en campos abandonados del Pirineo Central Español: análisis de los procesos de sucesión mediante imágenes Landsat (1984-2001). Pirineos, 161: 59-84.

Vicente-Serrano, S.M., PÉrez-Cabello, F., Lasanta, T. (en revisión). Assessment of radiometric correction techniques in analyzing vegetation variability and change using time series of Landsat images. Remote Sensing of Environment.

VRIELING, A. (2006). Satellite remote sensing for water erosion assessment: a review. Catena, 65: 2-18.

VRIELING, A., Sterk, G., VigiaK, O. (2006). Spatial evaluation of soil erosion risk in the West Usambara Mountains, Tanzania. Land Degradation \& Development, 17(3): 301-319.

WARREN, A. (2002). Land degradation is contextual. Land Degradation \& Development, 13: 449-459.

YAIR, A., RAZ-YASSIF, N. (2004). Hydrological processes in a small arid catchment: scale effects of rainfall and slope length. Geomorphology, 61: 155-169.

Zinck, J.A., LóPez, J., MetTernicht, G.I., Shrestha, D.P., VÁZquezselem, L. (2001). Mapping and modelling mass movements and gullies in mountainous areas using remote sensing and GIS techniques. International Journal of Applied Earth Observation and Geoinformation, 3: 43-53. 